\title{
Research on the Development of Japanese Ceramics
}

\author{
$\mathrm{Yu} \mathrm{Wu}{ }^{1}$ and Danyu $\mathrm{Wu}^{1}$ \\ ${ }^{1}$ Jingdezhen Ceramic Institute, Jingdezhen, Jiangxi 333403, China
}

\section{Keywords: Japanese; Ceramics}

\begin{abstract}
Japan is a developed industrial country, but also a big producer of ceramics, although the total number of sales is lower than China, but the output ratio has been much higher than China. many useful business, philosophy, advanced management experience, cultural cultivation in the history of the development of Japan ceramics are worthy of reference for international peer.

In the Ming dynasty, that is the Japanese Edo Yuan two years (1616), China's ceramic art is already very mature, both the official kiln and the folk kiln have been able to burn beautifully blue and white, bucket color, glaze color, underglaze color, while the Japanese still is the world of tough pottery. At that time the kiln worker Li Canping was swept from the North Korea to Japan, looking for the clay, until found the porcelain clay in the mountain of the river, this amazing discovery ignited the Japanese kiln fire, but also prompt the original small village hidden the wild mountains has become the world famous Japanese porcelain city.

400 years has passed when the first time of white kiln porcelain came out gloriously from the 17th century Japanese history, this area with only 37 million square kilometers of the island's ceramic industry has also undergone enormous changes, 35 ceramic production enterprises come from 43 Japanese cities, counties and villages, the ceramic enterprises almost all cover the whole Japan. During the four hundred years, Japan's ceramic industry has undergone what kind of changes, making this country later than China's more than a thousand years from backward porcelain industry development to the well-known porcelain country now, the formation of his industrial chain is worthy of in-depth study. After studying the ceramic industry model in Arita and throughout Japan, we found that the Porter diamond model can be used to analyze it.
\end{abstract}

\section{Make Full Use of Resource}

Arita is a town in the west of Kyushu, Japan located in western Saga Prefecture, Japan, the birthplace of fine white porcelain in Japan and is famous for one of Japan's traditional handicrafts, being the Arita burning. It is the Japenese porcelain city, known as "Japan's Jingdezhen". Township area of $65.80 \mathrm{~km}^{2}$, population of only 20,000 people, with more than 100 ceramic factories, $70 \%$ of residents are engaged in related work.

The Japanese government value the reputation of the Arita Burning, wasted huge money to build a ceramic-themed leisure park in the town, at present, it has become an internationally renowned tourist destination, named the Arita Ceramic Park. It is the biggest highlight of the whole is the simulation of Germany "Ziviweige Palace" to build the ceramic art museum, the statue of the palace, the column, corridors also imitate the vivid, even the pool before the palace is exactly the same, after going to it, it can give people a kind of feeling of walking in the town of Germany in eighteenth century. The museum's collection of world-renowned works of the fields, from the Edo period to the Meiji period works, they can clearly understand the historical evolution of Arita burning, and in 1870, Vienna World Expo exhibited $180 \mathrm{~cm}$ large vase, is one of must see collections in the museum, behind the possession of the garden it is a large garden and green Baroque garden, green vegetation is shaped into a variety of different shapes, creating an artistic atmosphere, looks pleasing, quite same like some European royal garden temperament. In the park, in the Arita burning studio you can experience the fun of pinching pottery, painting, even beginners can create a unique Arita burning. At the same time the end of April to early May it will be held the " Arita pottery city", in a short $4 \mathrm{~km}$ street, more than 650 ceramic shops opened, has been going for nearly a hundred years, and this alone will attract about millions of domestic and foreign tourists every year, has made tremendous contributions to the local economic development. 


\section{The Global Corporate Strategy}

Arita ceramic enterprises mainly undertake business supplies, home art orders, using the specialized division of production and management methods, mainly consisting of the manufacturers, suppliers, wholesalers, can control the risk to a great extent.

In addition to the fine division of labor in the professional efforts, these ceramic enterprises also pay great attention to the development of export-oriented business philosophy, they clearly know that the Japanese land area is small, with limited population, because no matter how much love the Japanese themselves to the porcelain, the resulting consumption is limited. So in addition to actively occupy the domestic market, the Japanese companies have long been doing their efforts to develop the international market, treating globalization as a business development preferences. Therefore, the business owner will study abroad market at least several times one year, applying the Japanese unique business survey to collect a variety of ceramic business and technical information, making them have a very deep understanding on the world ceramic production technology and product market trends in a long time, familiar with ceramic product varieties, production capacity and even raw material performance for every country.

In order to achieve the goal of product export-oriented development, the Japanese ceramic enterprises collect the different needs of ceramics, and to distinguish high, medium and low level in the product grade, using the corresponding raw materials and technology for manufacturing, forming different prices grade, to adapt to the United States, Europe and Southeast Asia, developing countries with different levels of consumption. And even if the production cost is high, the Japanese still use the process of relatively complex secondary firing, although the cost are increased, but its high-grade porcelain prices bring high profits far offset the cost of energy, over the years Japan's high-level ceramic products has been stable in the United States, Western Europe and other developed countries in the market, the Japanese ceramic reputation in the international community generally be well received.

\section{The Carefully Shaping of Brand}

Because of their lack of resources in Japan, so the Japanese has always played the greatest value of resources, this concept on the quality of the ceramic is reflected in their high-grade brand-name porcelain commodity positioning, which is precious like "artificial gem", so the sale of them are placed in the same window as gold and silver jewelry, diamond and jade for sale, but also through this way to indicate its elegant taste.

In addition to packaging, the Japanese ceramic production technology and technical equipment basically completed the automation and intelligent high-tech transformation. Such as continuous automatic processing of raw materials, high-strength magnetic iron removal process, isostatic pressing and hydroforming process, automatic glazing, automatic drying and even automatic control of calcination technology. In addition to a very small number of processes yet to be perfect, all mechanical parts can be replaced by artificial parts, are mechanized fully automated implementation of the operation process.

Although the uniqueness and implication of handmade products is far better than mechanical products, but the production efficiency of mechanical products is far more cost-effective than people's economy, it can reduce the cost of products at the same time can greatly avoid the manual operation of the product defects, get stable product quality. From the daily use, we can see that as long as the appropriate design is achieved in advance, the market share of mechanical products is more conducive to the shaping of the brand.

While in the process of management, the Japanese ceramic enterprises for the use of raw materials, fuels, refractories, molds, decorative materials and other materials have taken strict control methods for them being into the factory quality standards and the entire production process in the technical indicators and operational benchmarks, strictly do not make the raw materials, blank and semi-finished products enter the next process, to take full quality management system, avoid the product defects in the bud. Such as daily use of glaze, blank and other raw materials into the 
factory, generally it must go through chemical analysis, ray analysis, refractoriness, electron microscopy test totally 12 tests; to prevent the occurrence of porcelain surface black spots, raw materials usually go through sieving, 6 times the iron-removel and other technical measures. In this strict quality management system, the Japanese high-end complete sets of porcelain product quality level is as high as $95 \%$ or more, much higher than China's current level of finished product rate.

\section{The Formation of Cultural Development}

The geographical shape of Japan is slender, and although there is not much of the area, there is extreme cold of winter in Hokkaido, and there is hot summer in Kyushu, Okinawa, and it forms unique island culture and marine culture. Aesthetic consciousness as a part of the spiritual culture also has a profound historical and cultural characteristics.

The aesthetics of Japan in the long process of social history evolution, both by the impact of Chinese culture and because of their own different circumstances, gradually forming its own unique spiritual and cultural connotations. In ancient times, Japan chose to study China. The influence of Chinese culture on Japan can be traced back to the Sui Dynasty. By the time of the Tang Dynasty, the number and frequency of studying abroad from Japan came to China had formed a considerable scale. This time, the "Tang ambassador " has promoted the exchange of Chinese and Japanese culture, and brought China's outstanding ideology and culture and advanced feudal system into Japan, which had effectively promoted the development and progress of Japanese politics, economy and culture. China's porcelain culture and craft also profoundly affect Japan's life and development. Vietnamese porcelain exported to Japan, was in the late of Tang Dynasty, there are Tang San Cai, Celadon, White porcelain and underglaze porcelain and so on. In the year 894, Japan no longer sent ambassador to China, one side of the popular learning and imitation of Chinese culture was originally popular in Japan, "Tang Feng", gradually changed the Japanese local aristocratic culture as the representative of the "wind".

For the aesthetic analysis of Japanese ceramic art, rigidly adhere to the understanding of the form of Japanese ceramic art is more one-sided, Japan's ceramic art aesthetic is accompanied by the traditional aesthetic appearance of the gradual formation of the nation. "Empty", "loneliness" is the formation of the Japanese aesthetic concept in the middle ages. Ceramic art as the carrier of the traditional aesthetic of Japan, the "sincerity, loneliness, quiet, mystery" and other traditional Japanese aesthetic fusion were integrated into the works of ceramic artists, they will place their love of their own culture on the ceramic, make two become one.

In addition to the love of ceramic art, ceramics also occupy a very important position in Japan's "food", Japanese cuisine, pay attention to the harmony of "color, taste, device". In the system, the requirements are fresh ingredients, and more choice of fresh seafood as raw materials, such as fish, shrimp, etc.; care for knife use, make full use of the natural texture of cutting materials. Food of "material", pay attention to the ingredients; food of "reason", is about the dishes. This shows that the attention Japanese food on the vessel. The ancients cloud "beautiful food and the beautiful vessel," refined equipment add food, both for the professional home or experience the exotic diners, will be an unforgettable experience. Chinese Confucianism classic works of the "The Analects of Confucius," said, "quality wins the text, will be wild, text wins quality, will be history, gentle and then be a gentleman." emphasize the unity of the content and form, food containers are text, and food is the quality The Japanese food industry think that food is beneficial to the human body; the beautiful vessel is beneficial to the human mind. Exquisite utensils will have produced a happy impact on the human psychology. Therefore, the Japanese ceramics practitioners have been greatly respected, which also greatly promoted the development of their ceramic industry.

At present, China's annual output of ceramics has been more than 10 billion, the number of products in the world's ranked first. But in the product grade, it is still in the low-end, basically win by the number, a Japanese ceramic industry friends had good criticism: "The Chinese people only know to invent the technology, but not good at using and playing this technology ". Through the exploration of the development of Japanese ceramics, hope this article could play a little inspiration for the future development of China's ceramic industry. 


\section{Acknowledgements}

Fund Project: Jiangxi Provincial Humanities and Social Science Base Project, Jingdezhen City Science and Technology Bureau "Study on the Combination of the Industry Chain Construction of Jingdezhen Art Porcelain with Tourism Industry - Learn from Overseas Market System".

\section{References}

[1] Kyocera's successful trajectory [M]. China Friendship Publishing Company, (Japan) Inamori Kazuo, 2003

[2] World Modern Design History [M]. China Youth Publishing House, Wang by the book, 2002

[3] History of Japanese Ceramics [M]. Liaoning Pictorial Publishing House, Guan Tao, Wang Yuxin compile, 2001

[4] Japanese Ceramic Code [M]. Liaoning Pictorial Publishing House, Wang Yuxin, Guan Tao compile, 2000 